\title{
Using the March of Dimes “Becoming a Mom” Prenatal Program to Improve Maternal Attitudes and Knowledge
}

\author{
Amy K. Chesser, Ph.D. ${ }^{1}$, Nikki Keene Woods, Ph.D., MPH ${ }^{1}$,
}

Trisha V. Melhado, MPH ${ }^{2}$, Amanda Steventon, M.D. ${ }^{2}$

${ }^{1}$ Wichita State University Department of Public Health Sciences

${ }^{2}$ University of Kansas School of Medicine-Wichita

Department of Family and Community Medicine

\begin{abstract}
Background. Premature birth, low birth weight, birth defects, and Sudden Infant Death Syndrome were identified as issues contributing to infant mortality in Kansas by the state's Blue Ribbon Panel. The March of Dimes Becoming a Mom (BAM) prenatal program was implemented in four counties identified with high infant mortality rates and significant birth numbers (Geary, Saline, Sedgwick, and Shawnee) by the Kansas Blue Ribbon Panel. The purpose of this study was to identify the changes in prenatal attitudes, knowledge, and health outcomes among BAM program participants.

Methods. A collaborative community-based model incorporating multidisciplinary teams was created to address the health disparity gap in birth outcomes. Patients participated in multiple prenatal education sessions using a curriculum developed by the March of Dimes. A pre-/posttest design was implemented for the prenatal sessions. Changes in attitudes were assessed using descriptive statistics. Paired t-tests were used to assess the difference in knowledge questions from pre- and post-tests. Health outcomes were analyzed using descriptive statistics.

Results. Participants were 69\% White, 87\% spoke English, 64\% were under age 26, 41\% were employed full time, $45 \%$ had some high school or had a diploma, 39\% had Medicaid, and 49\% were enrolled in WIC $(\mathrm{N}=114)$. Participants demonstrated a statistically significant increase in knowledge among 14 out of 32 questions including: identifying signs of preterm labor, what to do during preterm labor, postpartum symptoms, and baby sleep position. There were also changes in prenatal attitudes including: need for prenatal care as soon as possible, continuing prenatal care when feeling healthy and not smoking during pregnancy. Relative frequencies were tabulated for week of delivery, infant birth weight, type of delivery, and presence of maternal and infant medical conditions.

Conclusion. The March of Dimes BAM program participants reported improvements in prenatal knowledge. The BAM program can improve maternal knowledge through a community-based collaborative model of care. The combined prenatal education program with quality prenatal care can result in better maternal and child health outcomes.
\end{abstract}

KS J Med 2015; 8(2):50-60.

\section{Introduction}

Infant mortality rates in the United States have declined in recent years. ${ }^{1}$ However, the mortality rate among Kansas infants remains higher than the national average, 7.5 deaths per 1000 births versus 6.7 deaths for 1000 births, respectively. ${ }^{1}$ The leading causes of infant death include short gestation, low birth weight, sudden infant death syndrome, and maternal complications of pregnancy. $^{2-3}$ Additionally, there continues to be a disparity in infant mortality by race/ethnicity, marital status, and maternal education. ${ }^{3}$ In underserved communities, frequently comprised of ethnic 
minority populations with decreased education and income, it may be particularly important to provide optimal prenatal care to address the social and environmental contributors of infant mortality.

Group prenatal care has the potential to impact some of the leading causes of infant death. $^{4-5}$ Group prenatal care has been established as a method to educate women about prenatal care without the time constraints of a traditional prenatal appointment. Patients learn by hearing about other group member's experiences and concerns, as well as participating in group discussions, which lead to social enrichment. $^{6}$ Group prenatal care has increased self-worth and self-confidence for participants. $^{7}$ In a randomized controlled trial, Ickovics et al. ${ }^{8}$ found that group prenatal education improved patient outcomes when compared to those in traditional prenatal care. Additionally, they identified multiple areas where group prenatal care is more beneficial than traditional prenatal care in areas such as scheduling, continuity of care, community building, less cost, and more providerpatient time.

A recent review paper evaluated previous studies that have compared group and individual prenatal care and found favorable outcomes related to group prenatal care. ${ }^{9}$ However, these studies focused primarily on the "Centering Pregnancy" group prenatal model. They lacked evidence describing how group prenatal care produces better outcomes than traditional prenatal care. They suggested that future research should look at other group prenatal programs with a focus on how the group educational setting is optimal.

The CenteringPregnancy ${ }_{\circledast}$ group prenatal model and curriculum has been well described and evaluated., ${ }^{4,10-13}$ However, while this program has proven effective, it may be economically infeasible for use in underserved communities or for widespread implementation. Additionally, as acknowledged by the CenteringPregnancy ${ }_{\circledast}$ investigation team, one model of group care may not be equally as effective for specific ethnic populations or in differing cultural and community settings. ${ }^{14}$ Therefore, the March of Dimes set forth to create a community collaborative model for prenatal education designed to meet the needs of various cultures and women in the community setting.

The Kansas Blue Ribbon Panel on Infant Mortality was formed in June 2009 with the purpose of identifying key issues contributing to Kansas infant mortality rates to provide recommendations to the Kansas Department of Health \& Environment. ${ }^{15} \mathrm{~A}$ statewide evaluation was conducted to identify those communities with both high infant mortality rates and significant birth numbers. The counties were Sedgwick, Geary, Shawnee, and Wyandotte. According to this evaluation, the leading causes for infant mortality in Kansas were premature birth/low birth weight, birth defects, and Sudden Infant Death Syndrome (SIDS).

Immediately following these recommendations, the Kansas Chapter of the March of Dimes developed plans for implementing birth disparities programs in targeted communities across the state with the philosophy that every effort should be made to prevent the occurrence of preterm birth and reduce the associated infant mortality rate. The purpose of implementing this program was to advance patient education, assist and augment existing public health services, and clinically intervene in prenatal and pre/interconception periods. The primary goal of the program was to decrease preterm birth by increasing awareness of causal factors while changing the attitudes and behaviors to impact community-specific risk factors and to implement prevention strategies. 
Two priority areas were targeted in Kansas: eliminating birth disparities and eliminating elective birth procedures (a delivery performed for a nonmedical reason such as induction or cesarean section). The community health education component utilizes the March of Dimes Becoming a Mom and Comenzando bien curricula within the county health department or other community setting. The clinical component utilizes the March of Dimes 39 Weeks Toolkit, a tested program that provides a road map to assist with system evaluation, prevent elective birth procedures, and reduce the instance of early-term births and neonatal intensive care admissions. Both programs have standardized evaluation tools to evaluate knowledge and maternal and infant health outcomes. The programs are in place in four locations across the state of Kansas, however, no control group is being evaluated for comparison.

The purpose of this study was to identify the changes in prenatal attitudes, knowledge, and health outcomes among program participants using the March of Dimes Becoming a Mom (MOD-BAM) group prenatal protocol in various locations in Kansas. This study was unique in that previous group prenatal research has not documented the benefits of the BAM program for Kansas despite poor birth outcomes across the state.

\section{Methods}

Participants. The MOD-BAM program was implemented in four counties (Geary, Sedgwick, Saline, and Shawnee) across Kansas with staggered implementation dates. These counties met specific implementation criteria (e.g., an organized group made up of various stakeholders and other pre-planning logistics). The evaluation focused on participant data from July 1, 2013 through Dec. 31, 2013 among those that collected both pre- and post-test data.
Measures. Group prenatal program participants' attitudes, knowledge, and breastfeeding intentions were assessed with a pre- (given at initial prenatal session) and post-test (given at final prenatal session). Prenatal attitudes were assessed with four questions on a Likert scale asking about smoking and alcohol use during pregnancy and two questions related to the importance of prenatal care. There were 31 knowledge questions asking participants to identify signs of preterm labor, steps to take when experiencing preterm labor, postpartum symptoms, and general prenatal health (Appendix A lists the prenatal knowledge questions). Birth health outcomes were collected from participants' medical records by designated clinical personnel involved with the community-based project. The number of women breastfeeding was obtained through self-report data.

Analysis. Descriptive analysis assessed attitude changes from pre- and post-test. Paired t-tests were used to assess knowledge differences from pre- to post-test. Descriptive statistics were used to describe health outcomes compared to Kansas averages and breastfeeding intention and follow through. All analyses were conducted with IBM SPSS version $20 .^{16}$

\section{Results}

Given the staggered implementation of the program, there were 323 participants during the study time period. The majority of the participants were not at the program completion stage, therefore, ineligible to take the post-test. However, 114 participants completed the MOD-BAM program during the study time period as indicated by having both pre- and post-test data.

Participants were predominately White (69.3\%), English speakers (86.6\%), under age 26 (64.0\%), Medicaid recipients (38.9\%), and employed full-time (40.7\%). Only $29.5 \%$ had a high school diploma. 
Almost half were in the Women, Infants, and Children program (WIC; Table 1).

Participant attitudes changed favorably for the importance of prenatal care questions and smoking and only slightly for alcohol use during pregnancy. On the pre-test, $51.8 \%$ of participants strongly agreed that a woman who gets prenatal care as soon as she finds out she is pregnant will have a healthier pregnancy; on the post-test, $65.8 \%$ strongly agreed. On the pre-test, $69.9 \%$ of participants strongly agreed that a pregnant woman should go for prenatal care even if she feels healthy; on the post-test, $88.5 \%$ strongly agreed. On the pre-test, $65.8 \%$ of participants strongly agreed that smoking during pregnancy is harmful to a baby's health; on the post-test, $88.6 \%$ strongly agreed. There was a slight positive attitude change related to alcohol use during pregnancy from pre- to post-test; women strongly disagreed they can drink alcohol during pregnancy without harming their baby $(86.7 \%$ and $87.8 \%$, respectively).

Table 1. Participant characteristics $(\mathrm{N}=114)$.

\begin{tabular}{|r|c|r|c|}
\hline \multicolumn{1}{|l|}{ Race/ Ethnicity } & $\mathrm{N}(\%)$ & Education & $\mathrm{N}(\%)$ \\
\hline White & $79(69.3)$ & Some high school & $17(15.2)$ \\
\hline Black & $13(11.4)$ & High school diploma & $33(29.5)$ \\
\hline Hispanic & $20(17.5)$ & Some college & $28(25.0)$ \\
\hline Other & $2(1.8)$ & College graduate & $25(22.3)$ \\
\hline Language & & Advanced degree & $9(8.0)$ \\
\hline Spanish & $15(13.4)$ & Private & $38(33.6)$ \\
\hline Age & & Medicaid & $44(38.9)$ \\
\hline$<16$ & $3(2.6)$ & Tricare & $8(11.5)$ \\
\hline $16-20$ & $31(27.2)$ & Uninsured & $13(11.5)$ \\
\hline $21-25$ & $39(34.2)$ & Other (not specified) & $10(8.8)$ \\
\hline $26-30$ & $27(23.7)$ & Employment & $44(40.7)$ \\
\hline $31-35$ & $11(9.6)$ & Full-time & $26(24.1)$ \\
\hline $36-40$ & $2(1.8)$ & Part-time & $38(35.2)$ \\
\hline $40+$ & $1(0.9)$ & Not employed & \\
\hline Enrolled in WIC & $54(48.6)$ & & \\
\hline & & & \\
\hline
\end{tabular}

Participants demonstrated a statistically significant increase in knowledge among 12 of 31 questions which focused on identifying signs of preterm labor, action to take during preterm labor, identifying postpartum symptoms, drug use while pregnant, and baby sleep position (Table 2). Participants had significant knowledge gains pre- to post-test in identifying all six signs of preterm labor correctly, including contractions $(78 \%$ to $91 \% ; \mathrm{p}=0.001)$, bleeding (83\% to $91 \%$; $p=0.019)$, baby pushing down (72\% to 88\%; p $=0.007)$, backache (66\% to $89 \%$; p < 0.001), belly cramps (48\% to 89\%; p < 0.001), and cramps that feel like a period (65\% to 93\%; $\mathrm{p}<$ 0.001). Ninety-three percent of participants correctly identified on the posttest that they should rest if they are experiencing preterm labor $(p=0.019)$. Correct responses on the post-test revealed that $67.6 \%$ of participants identified that excessive bleeding was not normal ( $\mathrm{p}=$ 0.049 ), $92.3 \%$ identified that differences in 
bladder control is normal ( $p=0.033$ ), and $76.9 \%$ identified that night sweats are normal $(\mathrm{p}=$ 0.002). All participants correctly identified that using drugs while pregnant is harmful and that babies should be put to sleep on their back ( $\mathrm{p}=0.045$ and $\mathrm{p}=0.001$, respectively). Among knowledge questions related to nutrition, including fruit, vegetable, and calcium intake, the

Table 2. Significant changes in prenatal knowledge.

\begin{tabular}{|r|c|c|c|}
\hline & Pretest & Posttest & $p$-value \\
\hline Preterm labor signs & $\%$ correct & $\%$ correct & \\
\hline Contractions & 78.4 & 90.8 & 0.001 \\
\hline Bleeding & 82.5 & 90.8 & 0.019 \\
\hline Baby pushing down & 72.3 & 88.4 & 0.007 \\
\hline Backache & 66.3 & 88.7 & $<0.001$ \\
\hline Belly cramps & 47.8 & 89.2 & $<0.001$ \\
\hline Period like cramps & 65.0 & 88.9 & $<0.001$ \\
\hline Preterm labor action-rest & 82.4 & 92.6 & 0.019 \\
\hline Postpartum symptoms & & & \\
\hline Bleeding & 53.4 & 67.6 & 0.049 \\
\hline Bladder control & 84.0 & 92.3 & 0.033 \\
\hline Night sweats & 55.6 & 76.9 & 0.002 \\
\hline Drugs use while pregnant & 96.4 & 100.0 & 0.045 \\
\hline Baby sleep position & 85.7 & 100.0 & 0.001 \\
\hline
\end{tabular}

Although not statistically significant, there were several areas where participants had low or diminished knowledge scores from pre- to post-test. Those areas included action to take during preterm labor: doing nothing and waiting for an hour or two for symptoms to go away (78\% to $77 \%$ ), postpartum fever ( $80 \%$ to $83 \%$ ), baby blues (84\% to 87\%), nonstop crying (73\% to $74 \%)$, panic (65\% to $68 \%$ ), lack of interest in baby ( $81 \%$ to $78 \%)$, drug use before pregnancy (89\% to $84 \%)$, and waiting before getting pregnant again (12\% to $15 \%)$.

During the reporting period, there were 31 birth outcomes abstracted from participants' medical records (Table 3). On three of the four outcome indicators, the importance of breast milk, and the importance of interacting with the baby, participants scored correctly pre- and posttest. 
birth. $83 \%$ of women reported they planned to breastfeed at pre-test and that increased to
$86 \%$ at post-test. The actual percentage of women breastfeeding was $84 \%$.

Table 3. Relative frequency of maternal and infant health outcomes among women participating in the Becoming a Mom/Comenzando Bien program.

\begin{tabular}{|c|c|}
\hline Outcome & $\mathbf{N}(\%)$ \\
\hline \multicolumn{2}{|l|}{ Weeks baby delivered } \\
\hline$<37$ weeks & $4(12.9)$ \\
\hline 37-39 weeks & $13(41.9)$ \\
\hline$>39$ weeks & $14(45.2)$ \\
\hline \multicolumn{2}{|c|}{ Low birth weight infant $(<5$ lb $8 \mathrm{oz})$} \\
\hline Yes & $29(93.5)$ \\
\hline No & $2(6.5)$ \\
\hline \multicolumn{2}{|l|}{ Vaginal delivery } \\
\hline Yes & $25(80.6)$ \\
\hline No & $6(19.4)$ \\
\hline \multicolumn{2}{|l|}{ Induction } \\
\hline Yes & $16(51.6)$ \\
\hline No & $14(45.2)$ \\
\hline Missing & $1(3.2)$ \\
\hline \multicolumn{2}{|l|}{ Cesarean delivery } \\
\hline Yes & $5(16.1)$ \\
\hline No & $21(67.7)$ \\
\hline Missing & $5(16.1)$ \\
\hline \multicolumn{2}{|c|}{ Maternal medical condition } \\
\hline Yes & $6(19.4)$ \\
\hline No & $18(58.1)$ \\
\hline Missing & $7(22.6)$ \\
\hline \multicolumn{2}{|l|}{ Infant medical condition } \\
\hline Yes & $6(19.4)$ \\
\hline No & $21(67.7)$ \\
\hline Missing & $4(12.9)$ \\
\hline
\end{tabular}

\section{Discussion}

The study findings demonstrated positive gains in prenatal attitudes, knowledge, and outcomes for participants in the Becoming a Mom program. Significant knowledge improvements included preterm birth and safe sleep; both are important factors related to infant mortality. Overall, there were knowledge gains in recognizing preterm labor, what action to take when experiencing preterm labor, postpartum symptoms, drug use while pregnant, and appropriate baby sleep positioning. A recent systematic review assessing the group model of prenatal care suggested that prenatal knowledge gains and health outcomes improvements show promise. ${ }^{18}$ However, 
the authors cautioned the interpretation of the findings due to the lack of published evidence and quality of the studies. The majority of studies were quasi-experimental or non-experimental in design. Our preliminary findings suggested the MOD-

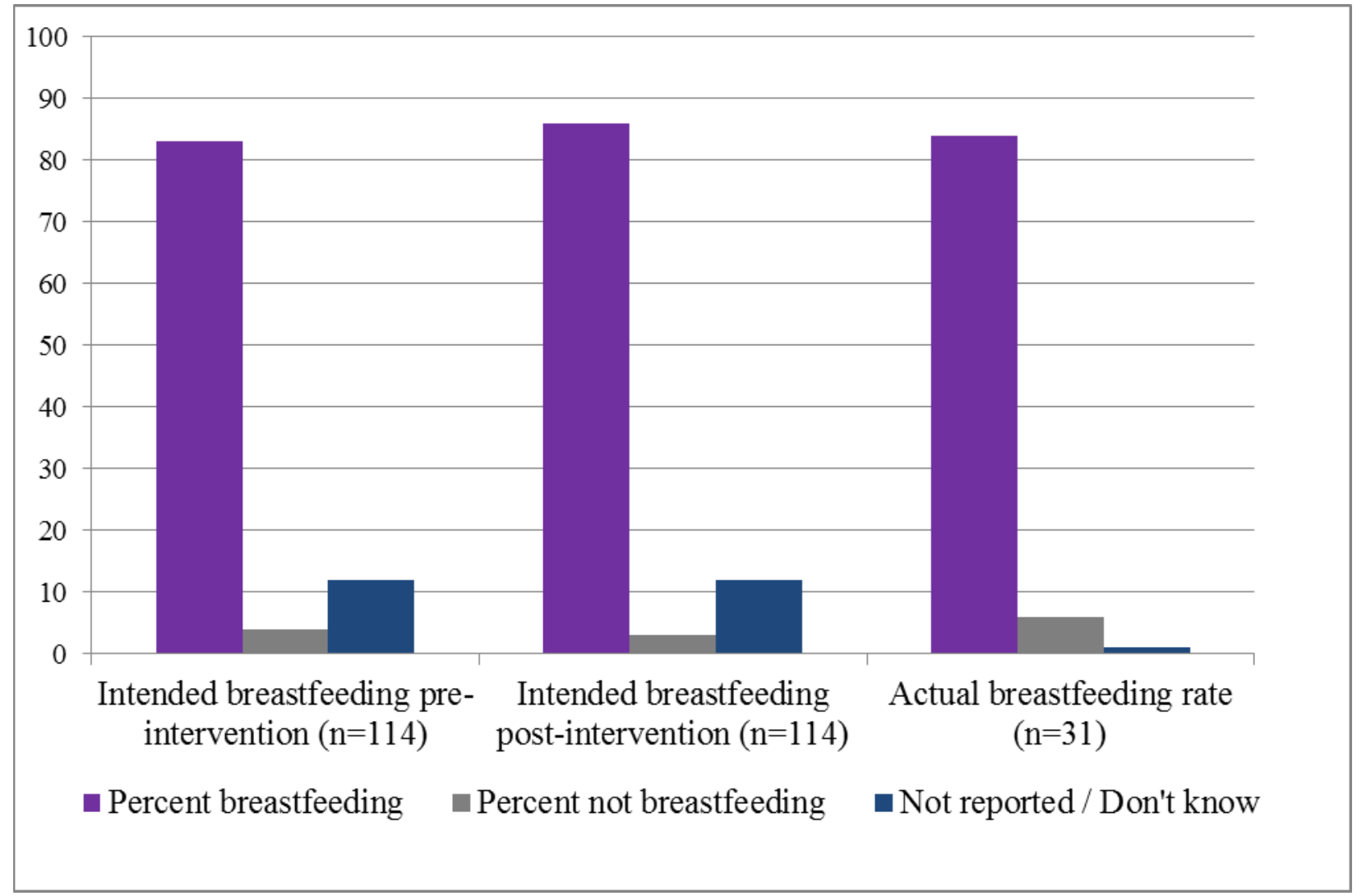

Figure 1. Percent of women intending to breastfeed pre-intervention and post-intervention and percent reporting breastfeeding after giving birth.

BAM program can improve maternal and child health outcomes when combined with quality prenatal healthcare. Vaginal delivery rate was $10.8 \%$ higher among participants. Breastfeeding initiation was reported by almost all participants, $11 \%$ more than the Kansas average. These findings supported the use of an enhanced community-based model of care using the March of Dimes curriculum.

There were several limitations to our study. Loss to follow-up and participant decay limited available data for program analysis. Multiple-site community-based programs often have a lack of program implementation fidelity. Each community implemented the Becoming a Mom group prenatal care in a way befitting their population, but not necessarily consistently between sites. The use of consistent evaluation tools and data collection procedures were used to mitigate these limitations.

Additional educational focus is warranted on actions to take during preterm labor besides rest; identifying normal verses abnormal postpartum symptoms such as fever, fatigue, baby blues, crying, panic, needing to nap, and lack of interest in baby; drug use before pregnancy; smoking; use of pain medication during labor; and baby's brain growth phase. As with most educational programs, there is room for improvement. The following topics warrant 
additional education to strengthen prenatal knowledge and improve birth outcomes: not waiting to call a provider if experiencing preterm labor, five of the ten signs of postpartum symptoms, not using drugs before pregnancy, and waiting before becoming pregnant again. Previous studies have shown that prenatal knowledge leads to better birth outcomes such as birth weight

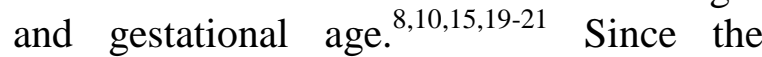
majority of knowledge gaps identified by the present study relate to postpartum symptoms, it will be important to emphasize the postpartum phase of pregnancy during prenatal sessions.

The March of Dimes Becoming a Mom group prenatal care has proven a viable, affordable model for educating pregnant women about prenatal health. In the Kansas counties where the MOD program was implemented, attitudes and knowledge of the participants changed favorably. Gaining knowledge through this collaborative community program about their pregnancies facilitated healthier choices by the participants, resulting in better birth and infant outcomes. Patients that acquired knowledge felt empowered to become active participants in their health and at the group meetings, resulting in better pregnancy outcomes.

Various aspects of MOD group prenatal care, such as increasing patient-provider time, scheduling ease, being cost-effective, and collaborating with other health professionals, are beneficial to the providers as well as the patients. ${ }^{5,7-9,14,18,21}$ The increased interaction allows providers to address potential social, psychological, and behavioral issues with the patients and potentially improve the health of the pregnancy and birth outcomes since those patients who see their provider more have more trust and communication than those with less frequent interactions. ${ }^{22}$ Since the MOD program teaches women about resources in the community based on their needs, they can have access to other health professionals which can enhance the services available to them, such as nutritional information, health education, and social services. These additional resources can increase the patient's health literacy aiding in improvement of maternal/ fetal outcomes.

As residency programs generally are comprised of a more diverse patient population with many health and social issues, this MOD program could be beneficial to the health outcomes of their pregnant patients. This program could be instituted in residencies and would provide assistance to communities that have poor maternal and fetal health outcomes while providing medical residents with the benefit of learning good perinatal care as well as learning to structure group visits. Group visits have shown successful outcomes with illnesses such as diabetes, obesity, asthma, and COPD. With this group visit structure, residents could conduct additional research with the focus of improving other perinatal and postnatal health outcomes of their patients. By using the group visit structure, education could be concentrated on the areas of concern to aid in favorable attitude and knowledge change and improvement of their community's perinatal and postnatal health outcomes. With wider implementation of the MOD program in other communities and residency programs with ethnic diversity, birth outcomes and maternal/fetal health could be improved and potentially decrease racial disparities of poor perinatal outcomes in these communities.

\section{Acknowledgements}

The authors acknowledge Diane Daldrup, Director, Greater Kansas Chapter of MOD, Shalae Harris RN, BSN, MPA, Program Coordinator Greater Kansas Chapter of 
MOD, and research assistants, Kyle Smothers, BS, and George Depew.

\section{Funding sources}

This work was funded through grants from the US Health Resources and Services Administration, the March of Dimes Greater

\section{References}

1 MacDorman MF, Mathews TJ, Centers for Disease Control and Prevention. Infant deaths - United States, 2005-2008. MMWR Surveill Summ 2013; 62(Suppl 3):171-175. PMID: 24264510.

2 Heron M, Hoyert DL, Murphy SL, Xu J, Kochanek KD, Tejada-Vera B. Deaths: Final data for 2006. Natl Vital Stat Rep 2009; 57(14):1-134. PMID: 19788058.

${ }^{3}$ Mathews TJ, MacDorman MF. Infant mortality statistics from the 2006 period linked birth/infant death data set. Natl Vital Stat Rep 2010; 58(17):1-31. PMID: 20815136.

${ }^{4}$ Carlson NS, Lowe NK. CenteringPregnancy: A new approach in prenatal care. MCN Am J Matern Child Nurs 2006; 31(4):218-223. PMID: 16940816.

${ }^{5}$ Ickovics JR, Kershaw TS, Westdahl C, et al. Group prenatal care and preterm birth weight: Results from a matched cohort study at public clinics. Obstet Gynecol 2003; 102(5 Pt 1):1051-1057. PMID: 14672486.

6 Novick G. CenteringPregnancy and the current state of prenatal care. J Midwifery Womens Health 2004; 49(5):405-411. PMID: 15351330.

7 Kilma CS. Centering Pregnancy: A model for pregnant adolescents. J Midwifery Womens Health 2003; 48(3):220-225. PMID: 12764308.

${ }^{8}$ Ickovics JR, Kershaw TS, Westdahl C, et al. Group prenatal care and perinatal outcomes: A randomized controlled trial. Obstet Gynecol 2007; 110(2 Pt 1):330339. PMID: 17666608.
Kansas Chapter, and the Department of Family and Community Medicine at the University of Kansas School of MedicineWichita.

9 Thielen K. Exploring the group prenatal care model: A critical review of the literature. J Perinat Educ 2012; 21(4):209218. PMID: 23997549.

${ }^{10}$ Bloom K. Use of the CenteringPregnancy program in a school-based clinic: A pilot study. Clin Excell Nurse Pract 2005; 9(4):213.

${ }^{11}$ Klima C, Noor K, Vonderheid S, Handler A. Introduction of CenteringPregnancy in a public health clinic. J Midwifery Womens Health 2009; 54(1):27-34. PMID: 19114236.

${ }^{12}$ Reid J. Centering Pregnancy: A model for group prenatal care. Nurs Womens Health 2007; 11(4):382-388. PMID: 17883755.

${ }^{13}$ Baldwin KA. Comparison of selected outcomes of CenteringPregnancy versus traditional prenatal care. J Midwifery Womens Health 2006; 51(4):266-272. PMID: 16814221.

${ }^{14}$ Robertson B, Aycock D, Darnell L. Comparison of centering pregnancy to traditional care in Hispanic mothers. Matern Child Health J 2009; 13(3):407414. PMID: 18465216.

${ }^{15}$ Kansas Blue Ribbon Panel on Infant Mortality. Infant Mortality in Kansas. April 2011 Fact Sheet. Available at http://www.kansasinfantmortality.org/files /Fact_Sheet.pdf

${ }^{16}$ IBM Corp. Released 2011. IBM SPSS Statistics for Windows, Version 20.0. Armonk, NY: IBM Corp.

${ }^{17}$ March of Dimes Foundation. March of Dimes 2013 Premature Birth Report Card. March of Dimes Foundation, 2013. 
Available at: http://www.marchofdimes. com/materials/prematurity-campaign-prog ress-report-2013.pdf.

${ }^{18}$ Sheeder J, Weber Yorga K, Kabir-Greher K. A review of prenatal group care literature: The need for a structured theoretical framework and systematic evaluation. Matern Child Health J 2012; 16(1):177-187. PMID: 21088988.

${ }^{19}$ Teate A, Leap N, Rising SS, Homer CS. Women's experiences of group antenatal care in Australia-the CenteringPregnancy pilot study. Midwifery 2011; 27(2):138145. PMID: 19386402.

${ }^{20}$ Grady MA, Bloom KC. Pregnancy outcomes of adolescents enrolled in a CenteringPregnancy program. J Midwifery
Womens Health 2004; 49(5):412-420. PMID: 15351331.

${ }^{21}$ Rising SS. Centering pregnancy. An interdisciplinary model of empowerment. J Nurse Midwifery 1998; 43(1):46-54. PMID: 9489291.

${ }^{22}$ Calo WA, Ortiz AP, Colon-Lopez V, Krasny S, Tortolero-Luna G. Factors associated with perceived patient-provider communication quality among Puerto Ricans. J Health Care Poor Underserved 2014; 25(2):491-502. PMID: 24858864.

Keywords: preconception care, health knowledge, attitudes, practice, prenatal education, Kansas

\section{APPENDIX A: Prenatal knowledge questions}

\begin{tabular}{|c|c|}
\hline 1 & $\begin{array}{l}\text { Sign of preterm labor: Contractions that make your belly tightening up like a fist } \\
\text { every } 10 \text { minutes or more. }(\mathrm{Y} / \mathrm{N})\end{array}$ \\
\hline 2 & $\begin{array}{l}\text { Sign of preterm labor: Change in the color of your vaginal discharge or bleeding } \\
\text { from your vagina. }(\mathrm{Y} / \mathrm{N})\end{array}$ \\
\hline 3 & Sign of preterm labor: The feeling that your baby is pushing down. $(\mathrm{Y} / \mathrm{N})$ \\
\hline 4 & Sign of preterm labor: Low, dull back pain. (Y/N) \\
\hline 5 & Sign of preterm labor: Belly cramps with or without diarrhea (Y/N) \\
\hline 6 & Sign of preterm labor: Cramps that feel like your period. (Y/N) \\
\hline 7 & $\begin{array}{l}\text { Should a pregnant woman do the follow if she is experiencing preterm labor: Call } \\
\text { her health care provider right away. (Y/N) }\end{array}$ \\
\hline 8 & $\begin{array}{l}\text { Should a pregnant woman do the follow if she is experiencing preterm labor: } \\
\text { Stop what she is doing and rest on her left side for one hour. (Y/N) }\end{array}$ \\
\hline 9 & $\begin{array}{l}\text { Should a pregnant woman do the follow if she is experiencing preterm labor: } \\
\text { Drink 2-3 glasses of water or juice (not coffee or soda). (Y/N }\end{array}$ \\
\hline 10 & $\begin{array}{l}\text { Should a pregnant woman do the follow if she is experiencing preterm labor: } \\
\text { Do nothing, and wait for an hour or two to see if the symptoms go away. (Y/N) }\end{array}$ \\
\hline 11 & $\begin{array}{l}\text { Should women take multivitamins with folic acid or prenatal vitamins after having a } \\
\text { baby? (Y/N) }\end{array}$ \\
\hline & $\begin{array}{l}\text { Are the following postpartum symptoms normal for a mother to experience after } \\
\text { delivery? }(\mathrm{Y} / \mathrm{N})\end{array}$ \\
\hline 12 & Bleeding more than a pad in an hour \\
\hline
\end{tabular}




\begin{tabular}{|c|c|}
\hline 13 & Fever \\
\hline 14 & Differences in bladder control \\
\hline 15 & Night sweats \\
\hline 16 & Fatigue (being tired) \\
\hline 17 & Baby blues for a day or two \\
\hline 18 & Nonstop crying \\
\hline 19 & Panic for no reason \\
\hline 20 & Needing to nap \\
\hline 21 & Lack of interest in your baby \\
\hline 22 & Is it important for a pregnant woman to eat more fruits and vegetables? $(\mathrm{Y} / \mathrm{N})$ \\
\hline 23 & $\begin{array}{l}\text { It is important for a pregnant woman to eat more calcium rich foods like cheese, } \\
\text { corn tortillas, broccoli and milk? (Y/N) }\end{array}$ \\
\hline 24 & Using drugs before getting pregnant is harmful to my future baby's health? (Y/N) \\
\hline 25 & Using drugs once during my pregnancy is harmful to my baby’s health? (Y/N) \\
\hline 26 & $\begin{array}{l}\text { It is ok to let people smoke around me while I am pregnant or around my baby once } \\
\text { he/she is born? (Y/N) }\end{array}$ \\
\hline 27 & $\begin{array}{l}\text { I have a choice whether or not to use pain medication during labor and delivery? } \\
(\mathrm{Y} / \mathrm{N})\end{array}$ \\
\hline 28 & $\begin{array}{l}\text { Are the last few weeks of pregnancy from week } 36 \text { to week } 39 \text { important for my } \\
\text { baby's brain growth and development? (Y/N) }\end{array}$ \\
\hline 29 & $\begin{array}{l}\text { Talking to, signing to, touching and smiling at your baby will help him/her form into } \\
\text { a secure baby and child. }(\mathrm{Y} / \mathrm{N})\end{array}$ \\
\hline 30 & Is breast milk best for a baby? $(\mathrm{Y} / \mathrm{N})$ \\
\hline 31 & How will you lay your baby down to sleep: (multiple choice) \\
\hline
\end{tabular}

